\title{
Predictors of quit intentions among adult smokers in Mauritius: Findings from the ITC Mauritius Survey
}

\author{
Susan C Kaai ${ }^{1}$, Jonet Chung-Hall ${ }^{1}$, Marie Chan Sun ${ }^{2}$, Premduth Burhoo $^{3}$, Leelmanee Moussa ${ }^{3}$, Mi Yan $^{1}$, Deerajen \\ Romasawmy ${ }^{2}$, Anne CK Quah ${ }^{1}$, Geoffrey T Fong ${ }^{1,4}$
}

\begin{abstract}
INTRODUCTION Mauritius has one of the highest rates of smoking in Africa. Smoking cessation is a priority for preventing tobacco-related morbidity and mortality. The purpose of this study is to identify the predictors of quit intentions among smokers in Mauritius in order to strengthen tobacco control policies and inform the development and delivery of services that may increase the likelihood of successful quitting.

METHods Data were drawn from Wave 1 (2009) of the International Tobacco Control (ITC) Mauritius Survey, a face-to-face cohort survey of a nationally representative sample of 598 adult smokers who were randomly selected from nine geographic districts in Mauritius using a multistage sampling procedure.

RESULTS The vast majority of smokers $(77.8 \%)$ had plans to quit smoking. Longer duration of past quit attempts ( 6 months or less), perceiving benefits of quitting, worrying about smoking damaging health in the future, and not enjoying smoking were significantly associated with quit intentions. However, socio-demographic characteristics, past quit attempts, overall attitude about smoking, and Heaviness of Smoking Index (HSI) were not associated with quit intentions.

concLusions The predictors of quit intentions among Mauritian smokers were generally similar to those found among smokers in other high- and middle-income countries. However, in contrast to findings in those other countries, nicotine dependence as measured by the HSI was not a significant predictor of quit intentions among Mauritian smokers. These findings highlight the need to consider the predictors of quit intentions when developing and delivering smoking cessation support services in Mauritius.
\end{abstract}

AFFILIATION
1 University of Waterloo,
Waterloo, Ontario, Canada
2 University of Mauritius,
Réduit, Mauritius
3 Mauritius Institute of
Health, Pamplemousses,
Mauritius
4 Ontario Institute for Cancer
Research, Toronto, Ontario,
Canada
KEYWORDS (ENGLISH)
smoking, predictors, Africa,
Cessation, quit intentions,
Mauritius
coRRESPONDENCE To
Dr. Susan C Kaai, University of
Waterloo, Waterloo, Ontario,
Canada, 200 University Avenue
West, N2L 3 G1 Waterloo,
Ontario, Canada. Email:
skaai@uwaterloo.ca

\section{INTRODUCTION}

Tobacco use continues to be the leading cause of preventable morbidity and premature death in the world. It is estimated that each year, tobacco use kills six million people (out of the one billion smokers), of which about $80 \%$ are from lowand middle-income countries ${ }^{1}$. Smoking cessation among adult smokers is critically important to improving public health initiatives because about $50 \%$ of smokers die from tobacco-related diseases ${ }^{1}$. Moreover, promoting cessation among smokers provides significant short-term and mediumterm benefits to reducing smoking-attributable diseases and mortality relative to prevention among non-smoking youth ${ }^{1}$. However, smoking is a complex behaviour that is difficult to change, and quitting tobacco use is challenging for many and often entails multiple quit attempts ${ }^{2,3}$.

Accordingly, numerous theoretical frameworks, including the Theory of Planned Behavior (TPB $)^{4}$, the Transtheoretical Model of Change (TTM) ${ }^{5}$, Social Learning Theory ${ }^{6}$, the Health Belief $\mathrm{Model}^{7}$, and Protection Motivation Theory ${ }^{8,9}$, have been used to explain and predict smoking behaviour and cessation. These theoretical models have identified a number of variables that influence smoking cessation such as intentions, selfefficacy, and perceived benefits, barriers, and vulnerability. Research has demonstrated that the intention to quit smoking, a core construct of models such as the TPB and TTM, is one of the strongest predictors of quit attempts ${ }^{10,11}$. Nevertheless, 
most previous studies focus on predictors of quit attempts ${ }^{10-22}$ and successful cessation ${ }^{10-12,15-24}$, while fewer studies investigate the predictors of intention to quit smoking ${ }^{22,25-27}$. Investigating the predictors of an intention to quit is invaluable to informing future cessation programs in Mauritius.

Existing research shows that the factors that are associated with quit intentions differ to some extent from the factors that are associated with other quit-relevant outcomes such as quit attempts and quit success (i.e., sustained quitting). For example, factors associated with quit attempts and smoking cessation include being white ${ }^{15,16}$, well-educated ${ }^{16}$, ${ }^{22}$, cohabiting/married ${ }^{15,22}$, lower nicotine dependence ${ }^{10,11,23}$,

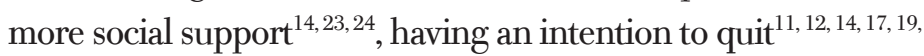
${ }^{21}$, consuming fewer cigarettes ${ }^{10,13,17,19}$, and high self-efficacy ${ }^{12,}$ 17, 18, 21, 24. Other factors like being older ${ }^{12,16,21,22,26}$, male $^{23}$, less exposure to smokers ${ }^{15}$, perceived benefits of quitting ${ }^{24}$, and previous abstinence from smoking ${ }^{21}$ are specific to smoking cessation, while being younger ${ }^{11,14,16}$ and having more negative attitudes towards smoking ${ }^{11,21}$ are associated with quit attempts. Known factors that are associated specifically with quit intentions include income ${ }^{28}$, education ${ }^{28}$, being male ${ }^{22}$, having attempted to quit in the past ${ }^{25,26}$, having longer duration of past quit attempts ${ }^{25}$, having lower nicotine dependence ${ }^{25}$, placing importance in quitting ${ }^{27}$, having self-efficacy ${ }^{27}$, worrying about future health, and having a bad opinion about smoking ${ }^{25}$. However, the vast majority of such studies on the factors that are associated with quit intentions, quit attempts, and quit success have been conducted in high-income Western countries.

Although research on the predictors of quitting in low- and middle-income countries (LMICs) is limited, there is evidence to suggest that on the whole, predictors of making quit attempts in LMICs are fairly similar to those found in high-income Western countries. For example, five studies examined quitting behaviours among smokers in Malaysia, Thailand, Hong Kong, and China ${ }^{17,21,22,25,26}$. Findings from these studies showed that, as in Western countries, quitting behaviours were associated with being male, having lower levels of nicotine dependence, having attempted to quit in the past, having higher levels of self-efficacy, having a history of longer previous quit attempts, having perceived benefits of quitting, and having concerns about the health effects of smoking.

But our knowledge of the factors that are associated with quit intentions and behaviours in Sub-Saharan Africa is almost non-existent. Although the mean prevalence of tobacco smoking among adults in the African Region is the lowest of all six WHO Regions (15.8\% in 2010), smoking is projected to rise considerably ${ }^{29}{ }^{30}$. In one simulation study ${ }^{29}$, smoking prevalence in the African Region will experience the largest increase in smoking prevalence by 2030 (21.9\%, representing a relative increase of $39 \%$ ). This is crucial because some countries in Africa have a prevalence of up to $48 \%$ for males and $20 \%$ for females ${ }^{31}$. Among the factors that will fuel this increase is the tobacco industry, which is increasing its efforts to build new markets in Africa. It is therefore critically important to understand the factors that are associated with smoking and with intentions to quit in Africa.

We know of only two studies in the African Region that have examined the predictors of intentions to quit. One study of adult smokers in Ethiopia found that smokers who had no intention to quit smoking had high nicotine dependence and low self-efficacy ${ }^{32}$. A second study of youth smokers in Nigeria showed that youth who had at least one smoking parent and perceived that smoking was socially acceptable were significantly less likely to have intentions to quit cigarette smoking ${ }^{33}$. Both of these studies were limited because study participants were drawn from community-based ${ }^{32}$ and schoolbased $^{33}$ convenience samples, thus the findings are not generalizable to the general population.

The present study focuses on the predictors of intentions to quit in the Sub-Saharan African country of Mauritius. It uses data from an ongoing national longitudinal cohort study of tobacco use and of the impact of tobacco control policies. This Mauritius study is part of the ITC Project, which has conducted similar cohort studies across 28 countries. The sampling design allows generalization of results to the entire country.

Mauritius has one of the highest smoking rates in Africa ${ }^{34}$. The most recent Non-Communicable Diseases Survey (2015) showed that adult smoking prevalence was $19.3 \%$, with higher smoking prevalence in men (38.0\%) than in women (3.9\%). Smoking prevalence was especially high among young adult males-more than $50 \%$ of males between the ages of 19 to 24 reported that they were smokers $^{35}$. In 2012, it was estimated that respiratory tract, oral, and stomach cancers - among the many cancers causally related to smoking - accounted for $24 \%$ of all new cancers among males, and $40 \%$ of male cancer mortality in Mauritius ${ }^{36}$. The Mauritius Ministry of Health and Quality of Life reported that each year there are 1,400 new cases of cancers and 950 deaths in Mauritius and about a quarter $(21 \%)$ of these deaths are attributable to smoking ${ }^{37}$. The WHO Framework Convention on Tobacco Control (FCTC) was signed by Mauritius on June 17, 2003 and ratified on May $17,2004^{38}$. In 2008, Mauritius launched a National Action Plan on Tobacco Control with goals to reduce tobacco-related mortality and morbidity through prevention of tobacco use among non-smokers, promotion of cessation 
among current smokers, and protection from exposure to secondhand smoke $\mathrm{e}^{39}$. On November 29, 2008, the Ministry of Health and Quality of Life passed the Public Health (Restrictions on Tobacco Products) Regulations, which are the principal regulations governing tobacco control in Mauritius ${ }^{40}$. These Regulations were implemented in two phases. Phase 1 (March 1, 2009) included regulations to strengthen policies banning smoking in public places, banning the sale of single cigarettes, and banning tobacco advertising, promotion, and sponsorship. Phase 2 (June-October 2009) regulations included the implementation of eight pictorial warning labels on cigarette packages, and banning misleading descriptors and product constituent yields on cigarette packages.

Mauritius has also made efforts to develop capacity and facilities to promote smoking cessation in Mauritius. In December 2008, a pilot smoking cessation clinic was launched. Seven cessation clinics were launched in the five regional hospitals in 2011. A July 2014 evaluation study showed an 18-20\% success rate (i.e., stayed quit 6 months or more) for participants who completed the program in the cessation clinics ${ }^{41}$.

Previous research in other countries has identified a wide range of factors associated with smoking cessation, but to our knowledge, there are no population-based studies of predictors of quit intentions in the African region. The present study is the first to examine predictors of quit intentions among a nationally representative sample of smokers in Sub-Saharan African country of Mauritius. The inclusion of individual-level predictors of quit intentions used in previous research in other ITC countries ${ }^{11,12,17,21,25}$ allows for the opportunity to identify predictors of quit intentions that are specific to the Mauritian context, as well as those that are similar across countries.

\section{METHODS}

\section{Study design}

The ITC Mauritius Wave 1 Survey is the first wave out of three nationally representative cohort surveys of the adult smokers and non-smokers in Mauritius. This survey is designed to evaluate the psychosocial and behavioural impact of tobacco control policies ${ }^{42,43}$. A multistage cluster sampling procedure was used to select the respondents from all the nine geographic districts of Mauritius: Black River, Flacq, Grand Port, Moka, Pamplemousses, Plaines Wilhems, Port Louis, Riviere du Rempart, and Savanne. A detailed description of the sampling and study design is available in the ITC Mauritius Wave 1 Technical Report ${ }^{44}$.

\section{Participants and survey procedures}

The respondents for this study were 598 adult smokers aged
18 years and older. Smokers were defined as those respondents who had smoked at least 100 cigarettes in their lifetime and smoked at least once a week at the time of the survey. Face-to-face interviews (about 60 minutes) were conducted in Mauritian Creole by trained interviewers between April and May 2009. The overall survey response rate was $89.8 \%$. Research ethics approval was obtained from the University of Waterloo Human Research Ethics Committee and the National Ethics Committee of Mauritius.

\section{Measures}

\section{Dependent variable}

Intentions to quit were based on responses to the question:"Do you plan to quit smoking?" Respondents who selected "in the next month", "in the next 6 months", or "sometime in the future after 6 months" were defined as having an intention to quit, and those who responded "not at all" were defined as having no intention to quit.

\section{Independent variables}

Socio-demographic variables were gender (male, female), age at the time of the survey $(18-24,25-39,40-54,55$ years and older), income (those with a monthly household income of $<10,000$ Mauritian Rupee (MUR) were coded as low, those between 10,000-24,000 MUR as moderate, and those $\geq 25,000$ MUR as high). Education was categorized as no education, low (primary education/Form 1 to 4), moderate (School Certificate [SC]/Higher School Certificate [HSC]/Vocational), and high (University degree or higher).

Quitting history variables assessed were: tried to quit smoking within the last year (yes, no), and longest time off smoking (never, less than 1 month, between 1-6 months, 6 months, or more). Nicotine dependence was measured using the Heaviness of Smoking Index (HSI; 7 levels, $0=$ least addicted to $6=$ =most addicted), which was based on the sum of two categorical variables: number of cigarettes smoked per day (CPD), $0=0-10,1=11-20,2=21-30,3=>30$ ), and time to first CPD $(0=>60$ minutes, $1=31-60$ minutes, $2=6-30$ minutes, $3=5$ minutes or less).

Motivational variables assessed were outcome expectancy of quitting, worries about health in the future, enjoyment of smoking, and overall attitude about smoking. Outcome expectancy of quitting (benefit from quitting in the next 6 months) was measured using the question: "How much do you think you would benefit from health and other gains if you were to quit smoking permanently in the next 6 months?" Response categories included: "not at all", "a little", and "very much". Worries about health in the future were measured by 
asking: "How worried are you, that smoking will damage your health in the future?" Response categories included: "not at all", "a little", and"very much."

Enjoyment of smoking was measured by asking for rating of agreement with the statement: "You enjoy smoking too much to give it up". The variable was coded into a threecategory variable: disagree (strongly disagree or disagree), neutral (neither disagree nor agree), and agree (agree or strongly agree). Overall attitude about smoking was measured by asking: "What is your overall opinion of smoking?" This variable was also coded as a two-category variable: Good (Very Good/Good/Neither Good Nor Bad), and Bad (bad/very bad). This measure is consistent with social psychological theory defining attitude as an evaluative judgment about a person, object, or issue ${ }^{45,46}$.

\section{Statistical analysis}

Weights were constructed with respect to smoking prevalence estimates by district. Logistic regression models were conducted to assess the predictors of intentions to quit, first in bivariate models, with each of the predictors of interest, and then in a multivariate model where the association between each predictor and the dependent variable was adjusted for all other variables in the models. Analyses were conducted using SAS 9.3.

\section{RESULTS}

Table 1 presents the socio-demographic characteristics of the sample. Most of the smokers (94.0\%) who were interviewed were men. Respondents were predominantly in the 25-39 (30.7\%) and $40-54$ years $(38.0 \%)$ age groups, with an average age of 44.2 years $(\mathrm{SD}=14.1)$. The majority $(88.8 \%)$ of respondents had an average monthly household income of less than 25,000 MUR (about $625 €$ ). About one-quarter (24.4\%) had no education and few (5.9\%) had a high level of education.

The vast majority $(90.8 \%)$ of respondents were daily smokers, with an average cigarette consumption of nine cigarettes per day (data not shown). More than two-thirds of Mauritian smokers $(77.8 \%)$ had plans to quit smoking. Of those planning to quit, almost one-quarter $(23.5 \%)$ planned to quit within 6 months. More than half (64.4\%) of respondents had tried to quit smoking at least once, and $53.2 \%$ anticipated that they would smoke less one-year post-survey.

Table 2 presents the results of the analyses that examined predictors of intentions to quit smoking. There were no significant differences in the percentage of smokers with quit intention across gender, income levels, and education in the
Table 1: Characteristics of the sample of Mauritian smokers

$\begin{array}{lll}\text { Tariable } & \text { Frequency } & \text { Percentage } \\ & \text { Gender } & \\ & 562 & \\ \text { Male } & 36 & 94.0 \\ \text { Female } & \text { Age Group } & 6.0 \\ & 47 & 7.9 \\ \mathbf{1 8 - 2 4} & 184 & 30.7 \\ \mathbf{2 5 - 3 9} & 227 & 38.0 \\ \mathbf{4 0 - 5 4} & 140 & 23.4 \\ \mathbf{5 5} & \end{array}$

$\begin{array}{lcc} & \text { Monthly Household Income (MUR) } \\ <10,000 \text { (low) } & 274 & 45.8 \\ \begin{array}{l}\text { 10,000-24,000 } \\ \text { (moderate) }\end{array} & 257 & 43.0 \\ \geq 25,000 \text { (high) } & 58 & 9.7 \\ \text { Not Stated } & 9 & 1.5 \\ & \text { Level of Education } & \\ \text { No education } & 146 & 24.4 \\ \text { Low (up to Form 1-4) } & 287 & 48.0 \\ \text { Moderate (School } & 130 & 21.7\end{array}$

Certificate/ Higher School

Certificate/ Vocational)

High (University Degree or $\quad 35 \quad 5.9$

higher)

$\begin{array}{lcc} & \text { Marital status } & \\ \text { Married } & 451 & 75.4 \\ \begin{array}{l}\text { Divorced or Separated or } \\ \text { Widowed }\end{array} & 36 & 6.0 \\ \text { Single } & 111 & 18.6 \\ & \text { Intention to quit } & \\ & 127 & 22.2 \\ \text { Does not plan to quit } & 446 & 77.8 \\ \begin{array}{l}\text { Plans to quit } \quad \text { Time to intention to quit } \\ \end{array} & \\ \text { Within the next month } & 50 & 8.7 \\ \text { Within the } 6 \text { months } & 85 & 14.8 \\ \text { Beyond } 6 \text { months } & 311 & 54.3 \\ \text { Not planning to quit } & 127 & 22.2\end{array}$

Ever tried to quit smoking

$\begin{array}{lll}\text { Yes } & 385 & 64.4\end{array}$

No $213 \quad 35.6$

Smoking how much 1 year from now

$\begin{array}{lll}\text { A lot more than now } & 16 & 2.7 \\ \text { A little more than now } & 21 & 3.6 \\ \text { The amount as now } & 206 & 35.3 \\ \text { A little less than now } & 174 & 29.9 \\ \text { A lot less than now } & 136 & 23.3 \\ \text { Not smoking at all } & 30 & 5.2\end{array}$


Research Paper

Table 2: Factors associated with intentions to quit smoking among Mauritian smokers

\begin{tabular}{|c|c|c|c|c|c|c|}
\hline & \multirow[b]{2}{*}{$\mathbf{N}$} & \multirow[b]{2}{*}{ Intentions to quit $(\%)$} & \multicolumn{2}{|c|}{ Univariate analysis } & \multicolumn{2}{|c|}{ Multivariate analysis } \\
\hline & & & Odds Ratio & $95 \% \mathrm{CI}$ & Odds Ratio & $95^{\circ} \% \mathrm{CI}$ \\
\hline \multicolumn{7}{|c|}{ Gender } \\
\hline Male & 417 & 76.9 & Ref & & Ref & \\
\hline Female & 29 & 76.3 & 0.972 & $0.403-2.342$ & 0.867 & $0.250-3.007$ \\
\hline \multicolumn{7}{|c|}{ Age Group } \\
\hline $18-24$ & 39 & 86.1 & Ref & & Ref & \\
\hline $25-39$ & 141 & 79.5 & 0.626 & $0.221-1.772$ & 1.091 & $0.241-4.944$ \\
\hline $40-54$ & 174 & 78.3 & 0.584 & $0.211-1.621$ & 0.716 & $0.172-2.977$ \\
\hline$\geq 55$ & 92 & 67.1 & 0.330 & $0.124-0.877$ & 0.464 & $0.103-2.097$ \\
\hline \multicolumn{7}{|c|}{ Household Income in MUR } \\
\hline$<10,000$ (low) & 210 & 78.3 & Ref & & Ref & \\
\hline $\begin{array}{l}10,000-24,000 \\
\text { (moderate) }\end{array}$ & 185 & 74.5 & 0.809 & $0.488-1.341$ & 0.955 & $0.479-1.905$ \\
\hline$\geq 25,000$ (high) & 46 & 82.8 & 1.334 & $0.595-2.988$ & 1.419 & $0.435-4.627$ \\
\hline Not reported & 5 & 64.1 & 0.496 & $0.128-1.925$ & 1.258 & $0.156-10.123$ \\
\hline \multicolumn{7}{|c|}{ Level of Education } \\
\hline No education & 104 & 71.7 & Ref & & Ref & \\
\hline $\begin{array}{l}\text { Low (Primary school / Form } \\
1 \text { to } 4 \text { ) }\end{array}$ & 221 & 79.4 & 1.526 & $0.852-2.733$ & 0.925 & $0.406-2.109$ \\
\hline $\begin{array}{l}\text { Moderate (School } \\
\text { Certificate / Higher School } \\
\text { Certificate / Vocational) }\end{array}$ & 94 & 75.1 & 1.193 & $0.617-2.306$ & 0.545 & $0.181-1.637$ \\
\hline $\begin{array}{l}\text { High (University level or } \\
\text { higher) }\end{array}$ & 27 & 81.4 & 1.726 & $0.680-4.377$ & 0.985 & $0.181-5.354$ \\
\hline \multicolumn{7}{|c|}{ Tried to quit within past year } \\
\hline Yes & 201 & 91.0 & Ref & & Ref & \\
\hline No & 243 & 68.1 & 0.211 & $0.126-0.353$ & 0.413 & $0.164-1.043$ \\
\hline \multicolumn{7}{|c|}{ Longest time off smoking } \\
\hline Never quit & 122 & 59.1 & Ref & & Ref & \\
\hline Less than 1 month & 139 & 86.2 & 4.330 & $2.506-7.483$ & 3.824 & $1.682-8.695$ \\
\hline $1-6$ months & 113 & 87.5 & 4.841 & $2.580-9.083$ & 3.476 & $1.513-7.986$ \\
\hline 6 months or more & 69 & 82.9 & 3.360 & $1.629-6.931$ & 1.692 & $0.663-4.320$ \\
\hline \multicolumn{7}{|c|}{ Heaviness of Smoking Index (HSI) } \\
\hline $0-6$ & 413 & * & 0.838 & $0.735-0.955$ & 1.016 & $0.805-1.283$ \\
\hline \multicolumn{7}{|c|}{ Outcome expectancy (benefits) of quitting } \\
\hline Not at all/ Slightly & 85 & 58.0 & Ref & & Ref & \\
\hline Benefit Moderately & 47 & 76.0 & 2.294 & $1.050-5.009$ & 1.614 & $0.629-4.140$ \\
\hline $\begin{array}{l}\text { Benefit Very much / } \\
\text { Extremely }\end{array}$ & 313 & 87.7 & 5.166 & $3.025-8.824$ & 4.503 & $2.273-8.919$ \\
\hline \multicolumn{7}{|c|}{ Worries about health in the future } \\
\hline Not at all & 62 & 56.1 & Ref & & Ref & \\
\hline A little / Moderately & 237 & 75.9 & 2.464 & $1.410-4.305$ & 1.173 & $0.553-2.488$ \\
\hline Very much & 143 & 94.5 & 13.489 & $5.649-32.205$ & 5.260 & $1.163-23.792$ \\
\hline \multicolumn{7}{|c|}{ Enjoyment of Smoking } \\
\hline Strongly Agree / Agree & 140 & 64.4 & Ref & & Ref & \\
\hline Neutral & 73 & 78.2 & 1.979 & $0.991-3.954$ & 2.905 & $0.818-10.312$ \\
\hline $\begin{array}{l}\text { Disagree / Strongly } \\
\text { Disagree }\end{array}$ & 230 & 86.9 & 3.669 & $2.080-6.472$ & 3.592 & $1.699-7.592$ \\
\hline
\end{tabular}


Attitude (Overall opinion) about smoking

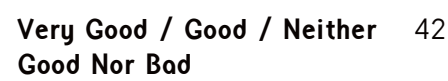

61.6

79.2
Ref

2.370
Ref

1.037
$0.456-2.359$

Ref: Reference category

Values in bold are those where the difference is statistically significant $(p<0.05)$.

* Heaviness of Smoking Index (HSI): See Method Section for the construction of this index. For smokers who had intentions to quit, the mean HSI was 1.36; for smokers who did not have intentions to quit, the mean HSI was 1.76 .

analyses. Age, past quit attempts (within the past year), HSI (nicotine dependence), and an overall negative opinion about smoking were significant in the univariate model but they were no longer significant once we controlled for other covariates in the multivariate analysis.

Smokers who reported some duration (i.e., time they went without smoking) of a past quit attempt were more likely to have a quit intention. Specifically, smokers who had a previous quit attempt lasting one to six months, were more likely to have a quit intention in comparison to those who had never quit.

Perceiving benefits from quitting, worrying about smoking damaging health in the future, and not enjoying smoking were also found to be significantly associated with quit intentions. This association was strongest among smokers who worried very much about their health in the future compared to smokers who were not worried at all.

\section{DISCUSSION}

This is the first study to examine the predictors of quit intentions among smokers in Mauritius and one of the very few that has examined this important topic among smokers in African countries. A number of studies have shown that socio-demographic characteristics such as age, gender, education, and income level are associated with intentions to quit smoking ${ }^{22,26-28}$. In our study, quit intentions were not independently associated with these socio-demographic characteristics. Our findings are consistent with previous research that has also failed to find an association between age, education, and income level and quit intentions ${ }^{14,25,47-49}$, and may be due in part to the effectiveness of the Mauritian national media campaigns that focus on educating the public on the harmful effects of smoking, the implementation of smoke-free policies in public venues, and the introduction of smoking cessation services in Mauritius.

Mauritian smokers have a high level of interest in quitting. Results from the present study showed that more than twothirds $(77.8 \%)$ of Mauritian smokers had intentions to quit. This finding is comparable with the intention to quit rates
(64.7\% to $81.5 \%)$ from four high-income ITC countries (Canada, USA, UK, and Australia) ${ }^{11}$, and higher than quitting rates from several other ITC countries including China $(24 \%)^{25}$, India $(33 \%)^{50}$, Thailand $(40 \%)$, and Malaysia $(58 \%)^{28,}$ 49. This finding highlights the need in Mauritius to strengthen cessation services to support smokers who are interested in quitting.

Consistent with Feng et al.'s study of smokers in China ${ }^{25}$, smokers in Mauritius who had a longer duration (time) off smoking, specifically, those who reported having a previous quit attempt lasting one to six months or less were more likely to have an intention to quit smoking in comparison to those who had never quit. This finding points to a need for health providers to design strategies to motivate smokers to quit in the knowledge that even if that quit attempt does not succeed, subsequent quit attempts will have a greater likelihood of succeeding. Additionally, health providers need to consider strategies that encourage smokers to have a longer duration off smoking i.e., lasting at least 6 months because it increases a smoker's likelihood of quitting smoking.

Mauritian smokers' perceptions regarding the benefits from quitting smoking (outcome expectancy), worrying about the health effects of smoking in the future, and not enjoying smoking were significantly associated with intention to quit smoking, consistent with studies conducted in other countries ${ }^{25}$, 26, 51. There is a need to sensitize Mauritian smokers on the harmful effects of smoking and the benefits of quitting, e.g., using sustained mass media campaigns.

While nicotine dependence as measured by the HSI is an important predictor of smoking cessation in ITC high-income countries $^{11,52,53}$, this study found that HSI was not associated with intentions to quit smoking among Mauritian smokers. A plausible explanation for this finding is the fact that the average daily consumption of cigarettes (CPD) in Mauritius is low (nine cigarettes per day) compared to the consumption in other ITC countries ${ }^{25,50}$, except for Mexico (8.6 cigarettes per day $)^{54}$. Perhaps this low consumption level $(\mathrm{CPD}<10)$ of cigarettes among Mauritian smokers is not an incentive to quit because they may not perceive themselves as addicted to 
tobacco and do not recognize the health risks associated with "low level" smoking. Moreover, light ("low level") smokers are less likely than heavier smokers to be advised about cessation when they visit health providers because they do not identify themselves as smokers ${ }^{55}$. It is interesting that this lack of association between dependence and quit intentions has been found in other smoker populations with lower levels of consumption including among Latino smokers in the US ${ }^{5,57}$. Our study findings suggest that anti-smoking programs in Mauritius need to emphasize the danger of tobacco use even at low levels ${ }^{58}$. The absence of an association between HSI and intentions to quit smoking among Mauritian smokers supports Siahpush et al. $\mathrm{s}^{28}$ observation that the existing knowledge (e.g., predictors of quit intentions) from high-income countries about disparities in smoking should not be generalized readily to LMICs.

This study has some limitations. The sample size of the female smokers is small. However, the impact of this limitation is minimized because the female sample was randomly selected and thus representative of the population of female smokers in Mauritius. In addition, the weights were constructed in such a way to remove or greatly diminish any bias that could have existed. It is also possible that responses may have been subject to recall bias due to self-reporting ${ }^{59}$. However, it is important to note that some of the usual sources of bias in the typical survey were likely fairly minimal in the ITC Mauritius Survey since our results are largely consistent with other ITC surveys $^{25}$. The cross-sectional analyses, limits conclusions about causality. Finally, quit intentions play an important role in getting smokers to make a quit attempt, which is a key step in the process of smoking cessation. However, it is worth noting that while the intention to quit smoking is associated with making a quit attempt, the success of a quit attempt is predicted by other factors such as nicotine dependence, selfefficacy and genotypes of the nAChR gene ${ }^{60-63}$. Moreover, there is evidence that intentions do not always translate into behaviours ${ }^{64,65}$. Further study of the multiple factors that affect smokers' attempts to quit and stay quit in different cultural contexts is warranted.

\section{CONCLUSIONS}

The predictors of quit intentions among Mauritian smokers were generally similar to those found among smokers in other high- and middle-income countries namely reporting a longer duration of past quit attempts, perceiving benefits of quitting, worrying about smoking damaging health in the future, and not enjoying smoking. However, in contrast to findings in those other countries, nicotine dependence as measured by the
HSI was not a significant predictor of quit intentions among Mauritian smokers. These findings highlight the need to consider the predictors of quit intentions when developing and delivering smoking cessation support services in Mauritius.

\section{CONTRIBUTOR STATEMENT}

GTF and PB were involved in the design of the study. DR and MY were responsible for the data analyses reported in this paper. SK, JCH, and MCS wrote the paper with contribution from GTF, ACKQ, MY, PB, and LM. All authors approved the final manuscript.

\section{REFERENCES}

1. World Health Organization. WHO report on the global tobacco epidemic 2015: Enforcing bans on tobacco advertising, promotion and sponsorship. 2015. Available at:http://apps.who.int/iris/bit stream/10665/178574/1/9789240694606_eng.pdf?ua=1\&ua=1 (accessed May 2016).

2. U.S. Department of Health and Human Services. The Health Consequences of Smoking-50 Years of Progress: A Report of the Surgeon General. Atlanta, GA: U.S. Department of Health and Human Services, Centers for Disease Control and Prevention, National Center for Chronic Disease Prevention and Health Promotion, Office on Smoking and Health. 2014.

3. DiClemente CC, Prochaska JO, Fairhurst SK, Velicer WF, Velasquez MM, Rossi JS. The process of smoking cessation: An analysis of precontemplation, contemplation, and preparation stages of change. J Consult. Clin Psychol.1991;59:295-305. http://dx.doi.org/10.1037/0022-006X.59.2.295.

4. Ajzen, I., \&Fishbein, M. Understanding attitudes and predicting social behavior. Englewood Cliffs, NJ: Prentice-Hall. 1980

5. Prochaska JO, Velicer WF. The transtheoretical model of health behavior change. Am J Health Promot. 1997;12(1):38-48.

6. Bandura A. Social foundations of thought and action: A social cognitive theory. Prentice-Hall, Inc; 1986.

7. Becker MH. The health belief model and personal health behavior. Charles B Slack; 1974.

8. Rogers R, Prentice-Dunn S. Protection motivation theory. In: Gochman D, ed. Handbook of health behavior research: Vol. 1. Determinants of health behavior: personal and social. New York: Plenum, 1997:113-32.

9. Boer H, Seydel ER. Protection motivation theory. In M. Conner, P. Norman (Eds.), Predicting health behaviour, Open University Press, Buckingham, UK (1996), pp. 95-120

10. Hellman R, Cummings KM, Haughey BP, Zielezny MA, O'Shea RM. Predictors of attempting and succeeding at smoking cessation. Health Educ Res.1991;6:77-86. doi: 10.1093/her/6.1.77.

11. Hyland A, Borland R, Li Q, McNeill A, Fong GT, O’Connor RJ, Cummings KM. Individual-level predictors of cessation behaviours among participants in the International Tobacco Control (ITC) Four Country Survey, Tob Control. 2006;15:iii83-iii94. doi:10.1136/tc.2005.013516.

12. Abdullah AS, Driezen P, Quah ACK, Nargis N, Fong GT. Predictors of smoking cessation behavior among Bangladeshi adults: Findings from ITC Bangladesh survey. Tobacco Induced Diseases. 2015.13(1). doi:10.1186/s12971-015-0050-y.

13. Vanasse A, Niyonsenga T, Coutreau J. Smoking cessation within the context of family medicine: which smokers take actions? Prev Med. 2004;38(3):330-7.

doi:10.1016/j.ypmed.2003.10.012. 
14. Venters MH, Kottke TE, Solberg LI, Brekke ML, Rooney B. Dependency, social factors, and the smoking cessation process: the Doctors Helping Smokers Study. Am J of Prev Med.1990;6:185-193.

15. Tucker JS, Ellickson PL, Orlando M, Klein DJ. Predictors of attempted quitting and cessation among young adult smokers.Prev Med. 2005;41:554-561. doi:10.1016/j.ypmed.2004.12.002

16. Hatziandreu EJ, Pierce JP, Lefkopoulou M, Fiore MC, Novotny TE, Giovini GA, Davis RM. Quitting smoking in the United States in 1986.J Nat Cancer Inst. 1990;82:1402-6. doi: 10.1093/jnci/82.17.1402.

17. Li L, Borland R, Yong HH, Fong GT, Bansal-Travers M, Quah AC, Sirirassamee B, Pmar M, Fotuhi O. Predictors of smoking cessation among adult smokers in Malaysia and Thailand: Findings from the International Tobacco Control Southeast Asia Survey. Nicotine Tob Res. 2010;12(Suppl 1):s34-s44. doi: 10.1093/ntr/ntq030.

18. Jardin BF, Carpenter MJ. Predictors of quit attempts and abstinence among smokers not currently interested in quitting. Nicotine Tob Res. 2012;14:1197-1204

doi: $10.1093 / \mathrm{ntr} / \mathrm{nts} 015$.

19. Clark, MA, Kviz FJ, Crittenden KS, Warnecke RB. Psychosocial factors and smoking cessation behaviors among smokers who have and have not ever tried to quit. Health Educ Res.1998;13:145-53. doi: 10.1093/her/13.1.145.

20. West R, McEwen A, Bolling K, Owen L. Smoking cessation and smoking patterns in the general population: a 1-year follow-up. Addiction. 2001;96:891-902. doi: 10.1046/j.1360-0443.2001.96689110.x.

21. Li L, Feng G, Jiang Y, Yong HH, Borland R, Fong GT. Prospective predictors of quitting behaviours among adult smokers in six cities in China: Findings from the International Tobacco Control (ITC) China Survey. Addiction. 2011;106:1335-45. doi: 10.1111/j.1360-0443.2011.03444.x.

22. Abdullah A, Yam H. Intention to quit smoking, attempts to quit, and successful quitting among Hong Kong Chinese smokers: Population prevalence and predictors. Am J Health Promot.2005;19:346-54. doi: http://dx.doi.org/10.4278/0890-1171-19.5.346.

23. Nides MA, Rakos RF, Gonzales D, Murray RP, Tashkin DP, BjornsonBenson WM, Lindgren P, Connett JE. Predictors of initial smoking cessation and relapse through the first 2 years of the Lung Health Study. J Consult Clin Psychol. 1995;63:60-9. http://dx.doi.org/10.1037/0022-006X.63.1.60.

24. Woodruff SI, Conway TL, Edwards CC. Socio-demographic and smoking related psychosocial predictors of smoking behavior change among high school smokers. Addict Behav. 2008;33:354-58. doi:10.1016/j.addbeh.2007.09.012.

25. Feng G, Jiang Y, Li Q, Yong HH, Elton-Marshall T, Yang J, Li L, Sansone N, Fong GT. Individual-level factors associated with intentions to quit smoking among adult smokers in six cities of China: Findings from the ITC China Survey. Tob Control. 2010;19:i6-11. doi: 10.1136/tc.2010.037093.

26. Yu D, Wu K, Abdullah A. Smoking cessation among Hong Kong Chinese smokers attending hospital as outpatients: Impact of doctors' advice, successful quitting and intention to quit. Asia Pac J Public Health. 2004;16(2):115-20. doi: $10.1177 / 101053950401600207$.

27. Wang SHQ, Borland R, Whelan A. Determinants of intention to quit: confirmation and extension of Western theories in male Chinese smokers. Psychology and Health 2005;20:35-51. doi:10.1080/08870440412331296062.
28. Siahpush M, McNeill A, Borland R, Fong GT. Socioeconomic variations in nicotine dependence, self-efficacy, and intention to quit across four countries: Findings from the International Tobacco Control (ITC) Four Country Survey. Tob Control. 2006;15(Suppl 3):iii71-5. doi:10.1136/tc.2004.008763.

29. Mendez D, Alshanqeety O, Warner KE. The potential impact of smoking control policies on future global smoking trends. Tob Control. 2013;22:46-51. doi:10.1136/tobaccocontrol-2011-050147.

30. Blecher EH, Ross H. Tobacco use in Africa: Tobacco control through prevention. Atlanta, GA: American Cancer Society. 2013.

31. World Health Organization. Policies for tobacco control in the African Region. Brazzaville:WHO Regional Office for Africa. WHO, 2013.

32. Girma E, Assefa T, DeribewA.Cigarette smokers' intention to quit smoking in Dire Dawa town Ethiopia: An assessment using the transtheoretical model. BMC Public Health 2010;10. doi:10.1186/1471-2458-10-320

33. Agaku I, Akinyele AO, Omaduvie UT. Evaluation of factors influencing intention to quit smokeless and cigarette tobacco use among Nigerian adolescents. Niger Med J 2012;53:31-6. doi: 10.4103/0300-1652.99829

34. Burhoo P, Mohee D, Moussa L. Mauritius. In: Drope J, ed. Tobacco control in Africa: people, politics and policies. New York: Anthem Press. 2011;p.185-200.

35. Ministry of Health and Quality if Life of Mauritius. The Mauritius Non-Communicable Diseases 2015 Survey.2015. Available at: http:// health.govmu.org/English/Statistics/Documents/Mauritius\%20 NCD\%20Survey\%202015\%20Report.pdf (accessed May 2016).

36. Manraj SS, Moussa L, Edoo R. Cancer Incidence and Mortality Report for 2012 in the Republic of Mauritius. Mauritius National Cancer Registry Report. 2012 (Unpublished).

37. Ministry of Health and Quality if Life of Mauritius. National Cancer Control Programme: Action Plan 2010-2014. 2010. Available at: http://www.iccp-portal.org/sites/default/files/plans/cancer-ap.pdf (accessed February 2016).

38. FCTC. World Health Organization, Framework Control on Tobacco Control. 2016. Available from: http://www.who.int/fctc/signatories_ parties/en/(accessed March 2016).

39. Ministry of Health and Quality of Life. National Action Plan on Tobacco Control 2008-2012. 2008. Available at: http://www.who. int/fctc/reporting/Annexfivemauritius.pdf (accessed March 2016).

40. Mauritius Government. The Public Health Act 2008 Regulations made by the Minister under sections 193 and 194 of the Public Health Act. Government Notice No. 263 of 2008. 2008. Available at: http://www.gov.mu/portal/goc/moh/file/tobaccol.pdf (accessed April 2016).

41. Mauritius. Evaluation of the tobacco cessation clinics of Ministry of Health and Quality of Life Report. Mauritius: WHO-AFRO; August 2014. (Unpublished).

42. Fong GT, Cummings KM, Borland R, Hastings G, Hyland A, Giovini GA, Hammond D, Thompson ME. The conceptual framework of the International Tobacco Control (ITC) Policy Evaluation Project. Tob Control. 2006;15 (Suppl 3):iii3-11. doi:10.1136/tc.2005.015438.

43. Thompson ME, Fong GT, Hammond D, Boudreau C, Hyland A, Borland R, Cummings KM, Hastings G, Siahpush M, Mackintosh AM, Laux FL. Methods of the International Tobacco Control (ITC) Four Country Survey. Tob Control. 2006;15(Suppl 3):iii12-18. doi:10.1136/tc.2005.013870.

44. ITC Project. (2010, January). ITC Mauritius Wave 1 (2009) 
Technical Report. University of Waterloo, Waterloo, Ontario, Canada, and Mauritius Institute of Health (MIH), Pamplemousses, Mauritius. Available at http://www.itcproject.org/files/Report_Publications/ Technical_Report/mu1_technical_report_january222010_final.pdf (accessed January 2016).

45. Petty, R. E. and Cacioppo, J. T. (1981), Attitudes and Persuasion: Classic and Contemporary Approaches. Dubuque, IA: Wm. C. Brown

46. Zanna, M. P., \& Rempel, J. K. (1988). Attitudes: A new look at an old concept. In D. Bar-Tal \& A. W. Kruglanski (Eds.), The social psychology of knowledge (pp.315-334). Cambridge, England: Cambridge University Press.

47. Reid JL, Hammond D, Driezen P. Socio-economic status and smoking in Canada, 1999-2006: has there been any progress on disparities in tobacco use?. C J Public Health. 2010; Jan 1:73-8.

48. Droomers M, Schrijvers CT, Mackenbach JP. Educational differences in the intention to stop smoking. The Eur J Public Health. 2004;14(2):194-8.

49. Siahpush M, Borland R, Yong HH, Sirirassamee B. Socio-economic variations in tobacco consumption, intention to quit and self-efficacy to quit among male smokers in Thailand and Malaysia: results from the International Tobacco Control-South-East Asia (ITC-SEA) survey. Addiction. 2006;103(3):502-8. doi: 10.1111/j.1360-443.2007.02113.x.

50. Surani NS, Gupta PC, Fong GT, Pednekar MS, Quah AC, BansalTravers M. Intention to quit among Indian tobacco users: Findings from International Tobacco Control Policy evaluation India pilot survey. Indian J Cancer. 2012;49(4):431-7. doi: 10.4103/0019-509X.107752.

51. Abdullah AS, Ho LM, Kwan YH, Cheung WL, McGhee SM, Chan WH. Promoting smoking cessation among the elderly: what are the predictors of intention to quit and successful quitting? J Aging Health. 2006;18(4):552-64. doi: $10.1177 / 0898264305281104$.

52. Hyland A, Li Q, Bauer JE, Giovini GA, Steger C, Cummings KM. Predictors of cessation behaviours in a cohort of current and former smokers followed over 13 years. Nicotine Tob Res. 2004;6(Suppl 3):S363-9. doi: 10.1080/14622200412331320761.

53. Fagan P, Augustson E, Backinger CL, O'Connell ME, Vollinger RE Jr, Kaufman A, Gibson JT. Quit attempts and intention to quit cigarette smoking among young adults in the United States. Am J Public Health. 2007;97:1412-20. doi: 10.2105/AJPH.2006.103697.

54. ITC Project (October 2009). ITC Mexico Survey Summary. University of Waterloo, Waterloo, Ontario, Canada, Instituto Nacional de SaludPublica, Cuernavaca, México, and University of South Carolina, Columbia, South Carolina, USA. Available athttp:// www.itcproject.org/files/Report_Publications/National_Summary/ itcmexico4pager.pdf (accessed April 2016).

55. Schane, R. E., Glantz, S. A., \& Ling, P. M. (2009). Nondaily and social smoking: An increasingly prevalent pattern. Archives of Internal Medicine, 169(19), 1742-1744.http://dx. doi.org/10.1001/archinternmed.2009.315.

56. Reitzel LR, Costello TJ, Mazas CA, Vidrine JI, Businelle MS, Kendzor DE, Wetter DW. Low-level smoking among Spanish-speaking Latino smokers: relationships with demographics, tobacco dependence, withdrawal, and cessation. Nicotine Tob Res. 2009;11:178-184. doi: $10.1093 / \mathrm{ntr} / \mathrm{ntn} 021$.

57. Rodriguez-Esquivel D, Cooper TV, Blow J, Resor MR. Characteristics associated with smoking in a Hispanic sample. Addict Behav. 2009;34:593-8. doi: 10.1016/j.addbeh.2009.03.030.
58. Swayampakala,K, Thrasher J, Carpenter MJ, Shigematsu LMR, Cupertino AP, and Berg CJ. Level of Cigarette Consumption and Quit Behavior in a Population of Low-Intensity Smokers Longitudinal Results from the International Tobacco Control (ITC) Survey in Mexico. Addict Behav. 2013;38:1958-65. doi: 10.1016/j.addbeh.2012.12.007.

59. Fidler AJ, Shahab L, West O, Jarvis M, McEwen, Stapleton JA et al. West R. 'The smoking toolkit study': a national study of smoking and smoking cessation in England. BMC Public Health. 2011;11:479. doi: 10.1186/1471-2458-11-479.

60. Smit ES, Hoving C, Schelleman-Offermans K, West R, de Vries $\mathrm{H}$. Predictors of successful and unsuccessful quit attempts among smokers motivated to quit. Addict Behav. 2014;39(9):1318-24.

61. Vangeli E, Stapleton J, Smit ES, Borland R, West R. Predictors of attempts to stop smoking and their success in adult general population samples: a systematic review. Addiction. 2011;106(12):2110-21.

62. Diemert LM, Bondy SJ, Brown KS, Manske S. Young adult smoking cessation: predictors of quit attempts and abstinence. Am J Public Health. 2013;103(3):449-53.

63. Kano M, Goto Y, Atsuta Y, Naito M, Hamajima N. Smoking cessation after genotype notification: pilot studies of smokers employed by a municipal government and those on Nagoya University medical campus. Nagoya J Med Sci. 2007;69(34);149-56.

64. Sheeran P. Intention-behavior relations: A conceptual and empirical review. Eur Rev Soc Psychol. 2002;12(1):1-36.

65. Armitage CJ, Conner M. Efficacy of the theory of planned behaviour: A metaanalytic review. Brit J Soc Psychol. 2001;40(4):471-99.

\section{ACKNOWLEDGMENTS}

The authors would like to acknowledge J. Ouimet (ITC Project Manager for the ITC Mauritius Wave 1 Survey) and the members of the ITC Mauritius team D. Mohee, V. LeClezio, and V. Pitchamootoo - for their contributions in planning and implementing the ITC Mauritius Survey, and the fieldwork team who conducted the interviews.

CONFLICT OF INTEREST The authors have completed and submitted the ICMJE Form for Disclosure of Potential Conflicts of Interest and none were reported.

\section{FUNDING}

This work was supported by the International Development Research Centre. Additional support was provided to GTF from a Senior Investigator Award from the Ontario Institute for Cancer Research and a Prevention Scientist Award from the Canadian Cancer Society Research Institute. The funding sources had no role in the study design, in collection, analysis, and interpretation of data, in the writing of the report, or in the decision to submit the paper for publication.

PROVENANCE AND PEER REVIEW

Not commissioned; externally peer reviewed 